\title{
PZT-Based Detection of Compactness of Concrete in Concrete Filled Steel Tube Using Time Reversal Method
}

\author{
Shi Yan, ${ }^{1}$ Jinzhi Fu, ${ }^{2}$ Wei Sun, ${ }^{1}$ Baohui Qi, ${ }^{3}$ and Fuxue Liu ${ }^{3}$ \\ ${ }^{1}$ School of Civil Engineering, Shenyang Jianzhu University, Shenyang, Liaoning 110168, China \\ ${ }^{2}$ Shenzhen China Overseas Construction Limited, Shenzhen, Guangdong 518057, China \\ ${ }^{3}$ Building Research Institute, Angang Construction Group, Anshan, Liaoning 114001, China
}

Correspondence should be addressed to Jinzhi Fu; fujinzhil@126.com

Received 11 October 2013; Revised 20 December 2013; Accepted 21 December 2013; Published 9 February 2014

Academic Editor: Ting-Hua Yi

Copyright (C) 2014 Shi Yan et al. This is an open access article distributed under the Creative Commons Attribution License, which permits unrestricted use, distribution, and reproduction in any medium, provided the original work is properly cited.

\begin{abstract}
A smart aggregate-based approach is proposed for the concrete compactness detection of concrete filled steel tube (CFST) columns. The piezoceramic-based smart aggregates (SAs) were embedded in the predetermined locations prior to the casting of concrete columns to establish a wave-based smart sensing system for the concrete compactness detection purpose. To evaluate the efficiency of the developed approach, six specimens of the CFST columns with the rectangular cross-section were produced by placing some artificial defects during casting of concrete for simulating various uncompacted voids such as cavities, cracks, and debond. During the test, the time reversal technology was applied to rebuild the received signals and launch the reversed signals again by SAs, to overcome the issue of the lack of the prototype. Based on the proposed nonprototype, two indices of time reversibility (TR) and symmetry (SYM) were applied to relatively evaluate the level of concrete compactness in the range of the two SAs. The experimental results show that the developed method can effectively detect the compactness of concrete in CFST columns.
\end{abstract}

\section{Introduction}

In civil engineering, concrete-filled steel tube (CFST) structures have extensively been applied due to advantages of high load bearing capacity, well seismic performance, good durability, and convenient construction. The unique mechanical property of a CFST structure makes it more competitive than concrete or steel structure. However, the comprehensive performance of a CFST member is associated with the compactness of concrete. The poor compactness of concrete for the CFST member may come from various defects such as cavities, cracks, and debond between steel and concrete due to the poor casting of concrete in site, shrinkage and creep development of concrete, weakening the overall performance of the CFST component. The defects are difficult to be evaluated since they hide in the steel tube. Therefore, the development of reliable monitoring techniques for the concrete compactness of CFST members has drawn extensive attention and some methods using nondestructive technology (NDT) are developed.
At present, the most commonly used technologies for nondestructive detection of concrete defect are ultrasonic pulse method, acoustic emission method, pulse echo method, ray method, radar method, infrared spectroscopy method, and so forth. However, the aforementioned methods are usually impractical and inconvenient for CFST structures. Therefore, further researches on the effectiveness for the concrete compactness detection of CFST structures are needed.

The piezoelectric-based approach has been widely recognized as one of the most promising active structural health monitoring (SHM) techniques for engineering structures in recent years due to the advantages of the availability in different shapes, quick response, broadband frequency, low price, and the ability of being employed as actuators and sensors simultaneously for damage detection. An array of piezoelectric transducers to a structure can be used to detect and localize disbands and deboning of advanced composite reinforcement from concrete structures according to the difference between the current transfer function and baseline transfer function for each actuator/sensor, as discussed by 
F
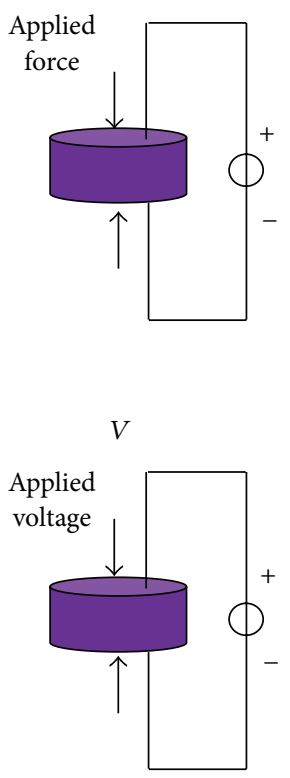

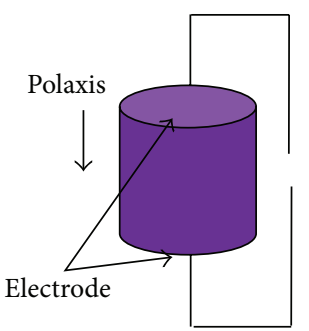

(a) Positive piezoelectric effect (sensor)
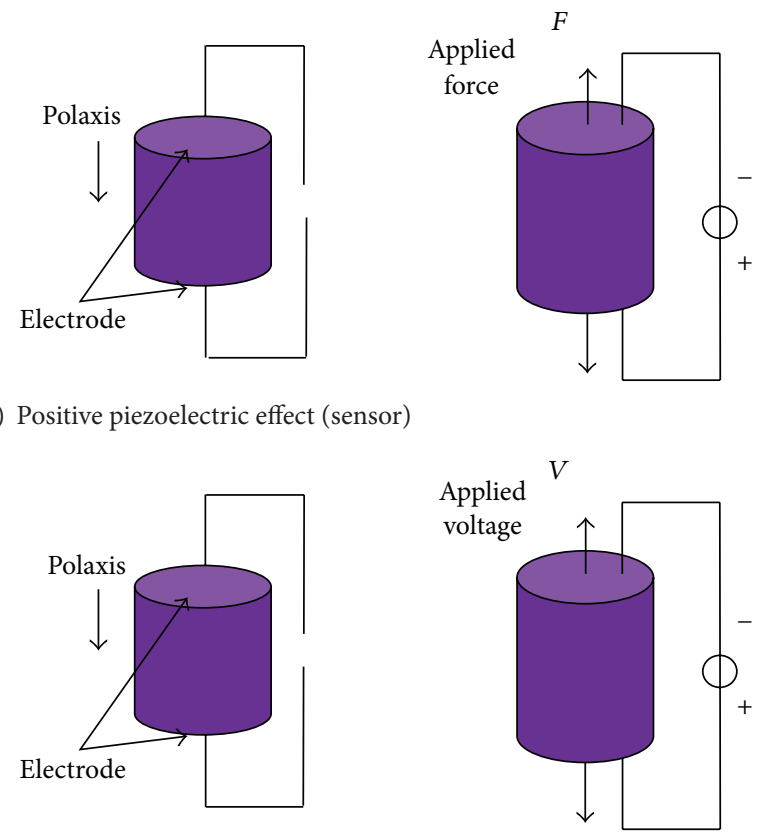

(b) Converse piezoelectric effect (actuator)

FIGURE 1: The schematic of piezoelectric effects.

Saafi and Sayyah [1]. An active diagnostic system was applied to detect embedded damage in fiber reinforced composite and steel reinforced concrete based on changes of sensor signal strength and arrival time before and after the introduction of damage. The results demonstrated the feasibility of using active sensing diagnostics for detecting deboning inside the structures, as discussed by Wang et al. [2]. An investigation was performed to detect deboning in reinforced concrete structures utilizing built-in piezoelectric patches as transducers in a pitch-catch mode to generate sensor data, which are sensitive to deboning in reinforced concrete structures, and the test results clearly indicated that deboning between concrete and rebar and yielding in rebar can be detected with the proposed method, as discussed by $\mathrm{Wu}$ and Chang [3]. A method was proposed for crack online monitoring of concrete compression columns based on piezoelectric sensors. The experimental results showed that the generation and development of the cracks are obviously companying with the phenomena of acoustic emission which can be detected by PZT sensors, as discussed by Yan and Sun [4]. A launch-receive interactive method to launch and receive signals was discussed by Qi et al. [5]. Euclidean distance was applied as an index to evaluate the concrete compactness. A validation test in situ was performed and the results showed that the worse concrete compactness in the location of the specimen clapboard was detected.

Usually, piezoelectric ceramic wave-based method for SHM needs a health status of the prototype structure to compare with the damaged one. However, it is very difficult to obtain the health status information of the structure. As a promising method, the time reversal technology (TRT) in signal processing theory needs no information of the prototype structure, and the state of the structure can be evaluated only by the information of the detected structure. Time reversibility of acoustic or body waves can be applied in lithotripsy, ultrasonic brain surgery, acoustic communications, and other nondestructive evaluations, as discussed by Fink [6]. The developed method opened a new way for SHM in civil engineering, as discussed by Song et al. [7, 8].

This study aimed at the detection of the compactness of concrete in CFST specimens by the use of both the piezoelectric ceramics (lead zirconate titanate, PZT) and the time reversal technology (TRT). For the validation of the proposed approach, six CFST specimens with various artificial defects were tested by using the PZT-based method, and two damage indices of time reversibility (TR) and symmetry (SYM) were applied. The results showed the feasibility and efficiency of the developed approach.

\section{Piezoelectric Effect and Smart Aggregates}

2.1. Piezoelectric Effect. Piezoelectric ceramics material such as PZT has the positive and converse piezoelectric effect, which can be used as both actuators and sensors, shown in Figures 1(a) and 1(b). Piezoelectric equations are expressed as follows.

Positive piezoelectric effect equation:

$$
\{\mathrm{T}\}=\left[\mathrm{c}^{\mathrm{E}}\right]\{\mathrm{S}\}-\left[\mathrm{e}^{\mathrm{t}}\right]\{\mathrm{E}\}
$$

converse piezoelectric effect equation:

$$
\{\mathrm{D}\}=[\mathrm{e}]\{\mathrm{S}\}+\left[\varepsilon^{\mathrm{S}}\right]\{\mathrm{E}\},
$$

where $\left[c^{\mathrm{E}}\right]$ is the elastic stiffness constant matrix; $\left[\varepsilon^{\mathrm{S}}\right]$ is clamping dielectric constant matrix; [e] is piezoelectric stress 


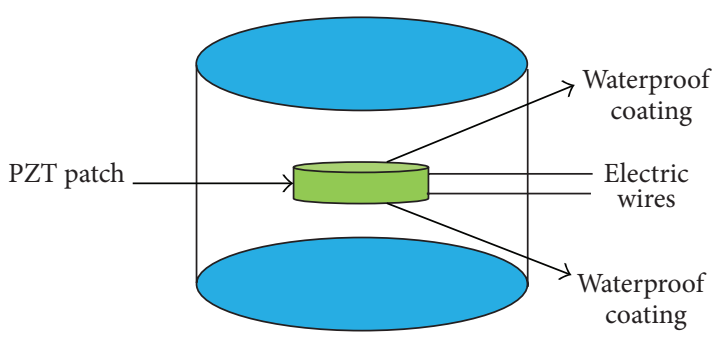

(a) The schematic of smart aggregates

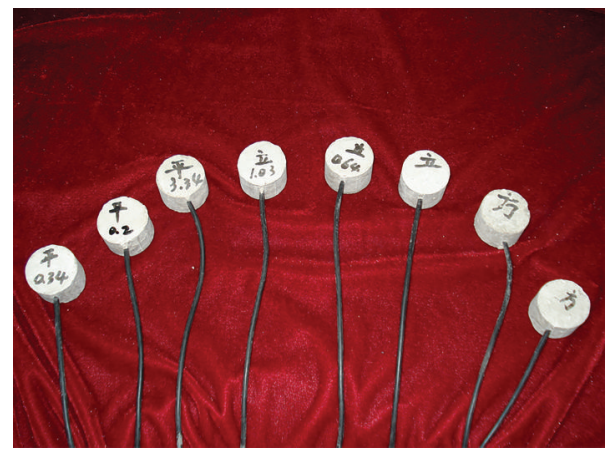

(b) Picture of smart aggregates

FIgURE 2: PZT-based smart aggregates.

constant matrix; $\left[\mathrm{e}^{\mathrm{t}}\right]$ is $[\mathrm{e}]$ the transposed matrix; $\{\mathrm{T}\}$ is the PZT stress vector; $[\mathrm{S}]$ is the PZT strain vector; $\{\mathrm{E}\}$ is the PZT electric field strength vector; and $\{\mathrm{D}\}$ is the PZT electric displacement vector.

2.2. Smart Aggregates. PZT-based smart aggregates (SAs) are produced by embedding a waterproof piezoelectric patch with shielded lead wires into a small concrete block, shown in Figure 2. The SA working as a real aggregate in a concrete structure plays a role in protecting PZT sheets. The SAs were embedded in the predetermined locations prior to the casting of concrete columns to establish a wave-based smart sensing system. SAs have properties of fast response, high sensitivity, and sensing and actuation double effect and are widely used in structural health monitoring research in the field of measurement [9-14].

\section{Algorithm of Concrete Compactness Detection Using Time Reversal Method (TRM)}

3.1. Time Reversal Method. Time reversal method (TRM) is a kind of adaptive technology that can lead beam focus and image in inhomogeneous medium. The French scientists Fink transformed the successful experience in optical application field into the acoustic one. So far, many experts and scholars have carried out a large number of theories and test research work. In recent years, time reversal lamb wave technology has been mature in the quality test of the infinite free boundary plate.

Because of adaptability of time reversal focusing and its automatic compensation of energy loss in the defect, it is

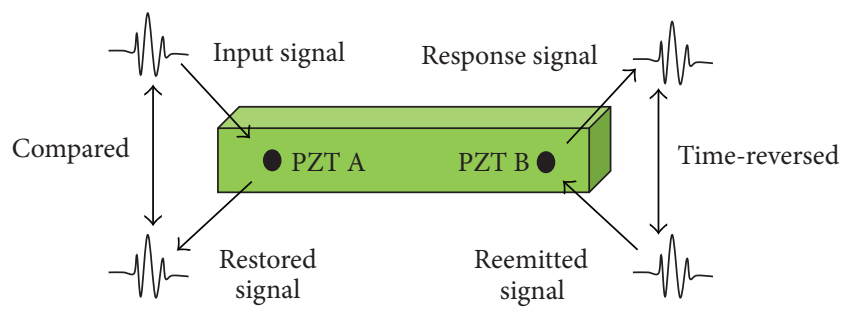

Figure 3: The schematic of damage detection using TRM.

suitable for any geometrical type of sensors. In addition, time reversal technology is based on the theory of guided wave propagation of the reciprocity principle, as discussed by Park et al. [15]. Therefore, this method is also applicable to the heterogeneous medium. Though sound field shape of each sensor vibration may not be the same, each time reversal sound wave reaches the maximum in the same place $R_{0}$ at the same time $T$, and a greater focus signal is obtained in the place $R_{0}$. Therefore, time reversal focusing becomes the first choice in heterogeneous medium.

Propagation principle of wave signal based on the time reversal technology is as shown in Figure 3.

When an arbitrary PZT patch (PZTA) is used as an actuator and another distinct PZT patch (PZTB) is used as a sensor, the response voltage at the sensing PZTB can be represented as follows:

$$
V_{B}(r, w)=I(\omega) K_{B}(\omega) K_{A}(\omega) G(r, \omega),
$$

where $r, I, K_{A}(\omega), K_{B}(\omega)$, and $G$ are the wave propagation distance from the center of the actuating PZTA to the sensing PZTB, the input voltage at PZTA, the mechanicalelectroefficiency constant of PZTA and PZTB, and the frequency response function of PZTB as a result of the input at PZTA, respectively.

As shown in Figure 3, once a response signal, propagating as the original input signal from PZTA, is measured at PZTB, the restored input signal at PZTA can be obtained by reemitting the time-reversed response signal at PZTB. Note that the time reversal operation of a signal in the time domain is equivalent to taking the complex conjugate of the Fourier transform of the signal in the frequency domain. Therefore, the time reverse operation on the response signal at PZTB is equivalent to taking the complex conjugate of (3) in the frequency domain:

$$
\widehat{\mathrm{V}}_{\mathrm{B}}^{*}(r, \omega)=I^{*}(\omega) K_{A}^{*}(\omega) K_{B}^{*}(\omega) G^{*}(r, \omega),
$$

where a superscript ${ }^{*}$ denotes a complex conjugate.

The restored signal at PZTA from the reemitted signal at PZTB can be represented in a similar form as (3):

$$
\begin{aligned}
V_{A}(r, \omega)= & K_{A} \widehat{\mathrm{V}}_{\mathrm{B}}^{*}(r, \omega) K_{B}(\omega) G(r, \omega) \\
= & I^{*}(\omega) K_{A}^{*}(\omega) K_{B}^{*}(\omega) K_{A}(\omega) \\
& \times K_{B}(\omega) G(r, \omega) G^{*}(r, \omega) \\
= & I^{*}(\omega) K_{A B}^{*}(\omega) K_{A B}(\omega) G(r, \omega) G^{*}(r, \omega),
\end{aligned}
$$




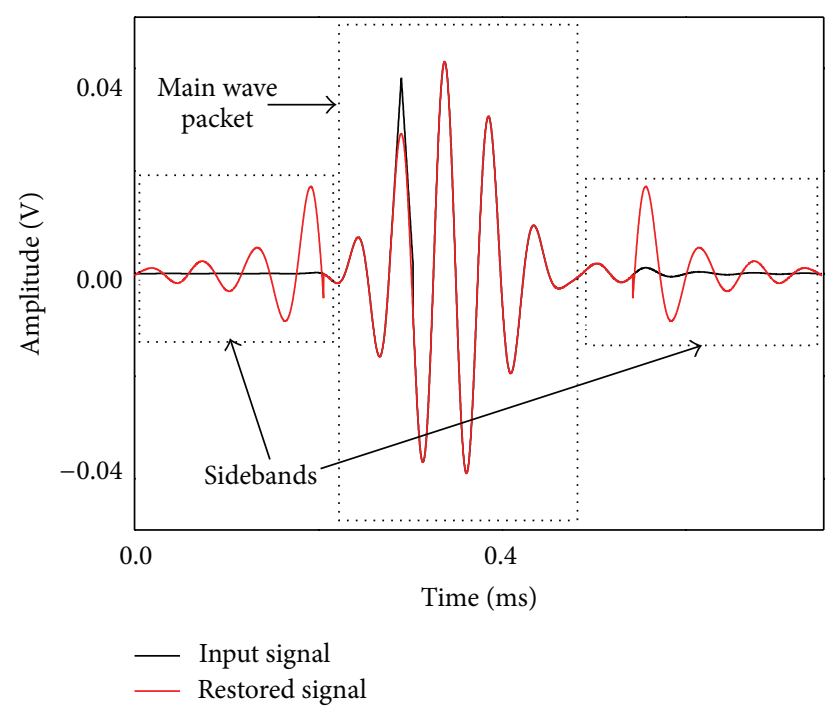

FIGURE 4: Comparison between restored signal and input one.

where $K_{A B}(\omega)$ denotes the product between $K_{A}(\omega)$ and $K_{B}(\omega)$. Therefore, the original input signal cannot be properly restored if abroad band input signal is used.

3.2. Compactness Index. Compactness detection of concrete using the time reversal process is based on the premise that, if there are certain types of defects along the wave propagation path, time reversibility breaks down. More precisely, the shape of the restored signal's main wave packet will depart from that of the original input signal and the symmetry of the restored signal is violated. By examining the deviation of the restored signal's main wave packet from the known input signal or the violation of the restored signal's symmetry as shown in Figure 4, certain type of damage can be identified without requiring any previously obtained baseline signals.

Based on this premise, two indices of time reversibility TR and symmetry SYM are applied for damage identification [16]. For the experimental study presented in the paper, a fivepeak pulse signal is used for excitation; $t_{l}$ and $t_{r}$ represent the starting and ending time points of the five-peak pulse signal, respectively, as defined in Figure 5.

The TR index, defined below, compares the waveform of the original input with that of the restored signal:

$$
\mathrm{TR}=1-\sqrt{\frac{\left[\int_{t_{l}}^{t_{r}} I(t) V(t) d t\right]^{2}}{\left[\int_{t_{l}}^{t_{r}} I(t)^{2} d t \int_{t_{l}}^{t_{r}} V(t)^{2} d t\right]}},
$$

where $I(t)$ and $V(t)$ represent the known input signal and the main wave packet in the restored signal, respectively. The value of the TR index becomes zero when the shape of the main wave packet in the restored signal is identical to that of the original input signal. The amplitude scaling difference between $I(t)$ and $V(t)$ does not affect the TR value. If $V(t)$ deviates from $I(t)$, the TR index value increases and approaches 1.0, indicating the existence of damage along the wave propagation path.

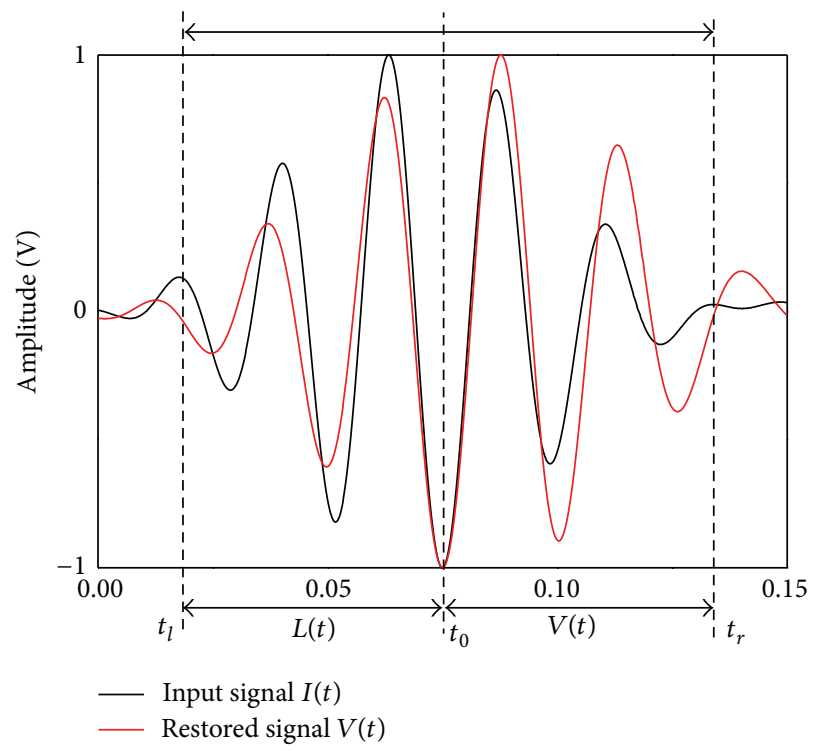

Figure 5: Parameter definition in the damage index.

The SYM index measures the degree of symmetry of the restored signal with respect to the main wave packet in the middle:

$$
S Y M=1-\sqrt{\frac{\left[\int_{t_{0}}^{t_{r}} L(-t) R(t) d t\right]^{2}}{\left[\int_{t_{l}}^{t_{0}} L(t)^{2} d t \int_{t_{l}}^{t_{r}} R(t)^{2} d t\right]}},
$$

where $L(t)$ and $R(t)$ represent left-hand and right-hand sides of the restored signal with respect to the main wave packet; $t_{0}$ is center time point of the main wave packet; $t_{l}$ and $t_{r}$ are as same as those defined for the TR index. All terms are shown in Figure 5. Because time reversibility is based on the linear reciprocity of elastic waves, one propagating from PZTA to PZTB and the other from PZTB to PZTA should be identical for the same input signal when the system stays in a linear regime. This linear reciprocity is shown to break down when there is damage along the wave path.

\section{Results and Discussion}

\subsection{Verification Experiment}

4.1.1. Basic Introduction. In order to validate the feasibility of the proposed method, a full size CFSTC is produced. The size of the column is $300 \times 300 \times 3000 \mathrm{~mm}$. The tube is divided into three parts linked by two partitions, shown in Figure 6 .

For comparison of the compactness of concrete in the CFSTC, two artificial defects $(100 \times 100 \times 10 \mathrm{~mm})$ are fixed at the bottom of the tube, while the top of the tube is cast in the normal process. Five SAs are buried in the concrete as actuators and sensors for active health monitoring. The location of the SAs and the photo of the specimen are shown in Figures 6 and 7, respectively. 


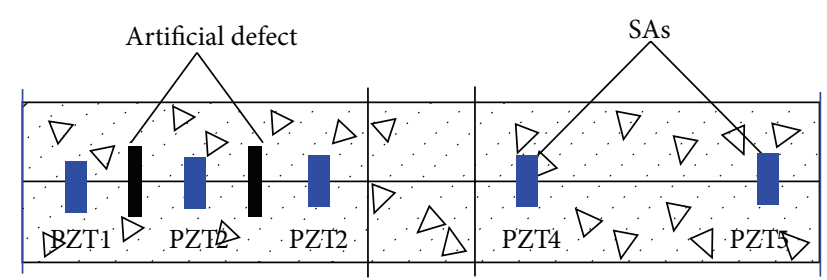

FIgURE 6: The artificial defects and the location of SAs.

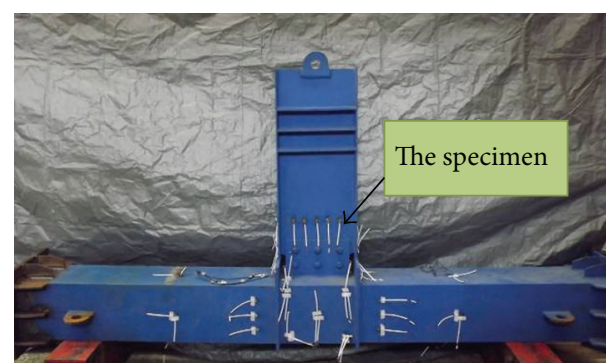

FIGURE 7: The specimen.

4.1.2. Experimental Setup. In this experiment, a five-peak pulse signal of $10 \mathrm{kHz}$, which is generated by RIGOL DG1022 arbitrary waveform/function generator, is used to excite the SAs in the center of the columns. The other SAs in the CFST column are used as sensors, whose signals are recorded through DS1000E digital oscilloscope. An amplifier for driving the piezoelectric ceramic is used for increasing the amplitude of the test signal. Figure 8 shows the experimental setup. The five-peak pulse signal is shown in Figure 9.

4.1.3. Test Results Analysis. Here are the three settled test groups, PZT1-PZT2 (group A), PZT2-PZT3 (group B), and PZT4-PZT5 (group C). Based on the above-mentioned test principle, an input signal is applied to PZTA, the corresponding response is measured at PZTB, the response at PZTB is reversed in the time domain and applied back to PZTB, and the final response is measured at PZTA. Before comparison, the restored signal is scaled so that the shape of the main wave packet in the restored signal can be better compared with that of the input signal. The results are shown in Figure 10.

We can find that the shape of the restored signal's main wave packet of group A and group B departs from that of the original input signal. Because there exist artificial defects between the two test groups, the amplitude attenuation occurs in the process of spread. Therefore, the symmetry of the restored signal is violated. The restored signal's main wave packet of group $\mathrm{C}$ is almost identical to the original input signal, and the symmetry of the restored signal is good. This is because the compactness of the concrete in group $\mathrm{C}$ is good. Linear reciprocity of this method has no damage. The validity of this method is proved.

The two compactness indices of the specimen are shown in Figures 11 and 12, respectively.

TR index values of the test groups $\mathrm{A}$ and $\mathrm{B}$ are 0.531 and 0.497 , respectively, while that of group $C$ is 0.143 . The values of groups A and B are three times that of group C.

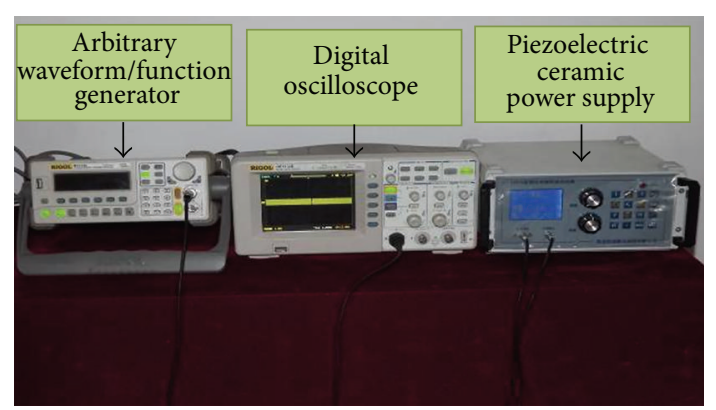

Figure 8: The experimental setup.

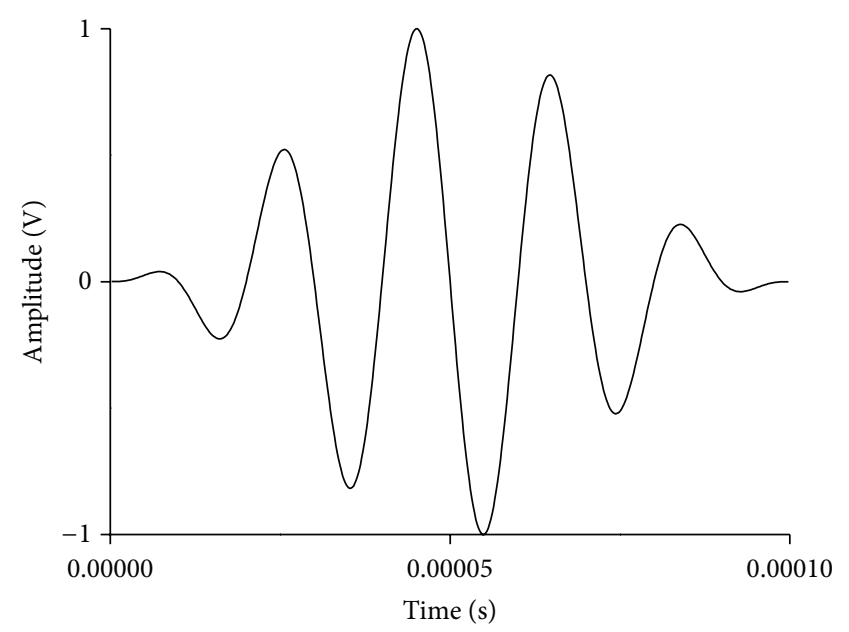

FIGURE 9: Input wave.

In fact, the values of group $C$ should be zero. However, the wave transmission cannot ensure to be totally linear due to different concrete interfaces, resulting in the nonzero values of the group C. Based on the above reasons, the result is reasonable. While the SYM index values of these test groups are $0.432,0.491$, and 0.098 , the same conclusion can be obtained.

So far, we know that this method used for compactness detection of CFSTC is feasible and effective. Next, a lot of tests will be conducted for the purpose of the comprehensive analysis of common defects in the CFSTC. Meanwhile this technology provides a new way for active monitoring and damage detection online for defects of concrete structures.

\subsection{Application of Time Reversal Method}

4.2.1. Description of Experiments. For further analysis of common defects of CFSTC, other five specimens are designed and produced. The differences among these specimens are types of defects and the size of defects, such as holes and deboning between steel and concrete. In order to find out the main influencing factors for concrete compactness, the diameters of partitions are $150 \mathrm{~mm}$ and $180 \mathrm{~mm}$, respectively. Parameters of specimens are shown in Table 1.

The artificial defects and the location of SAs are shown in Figure 13. 


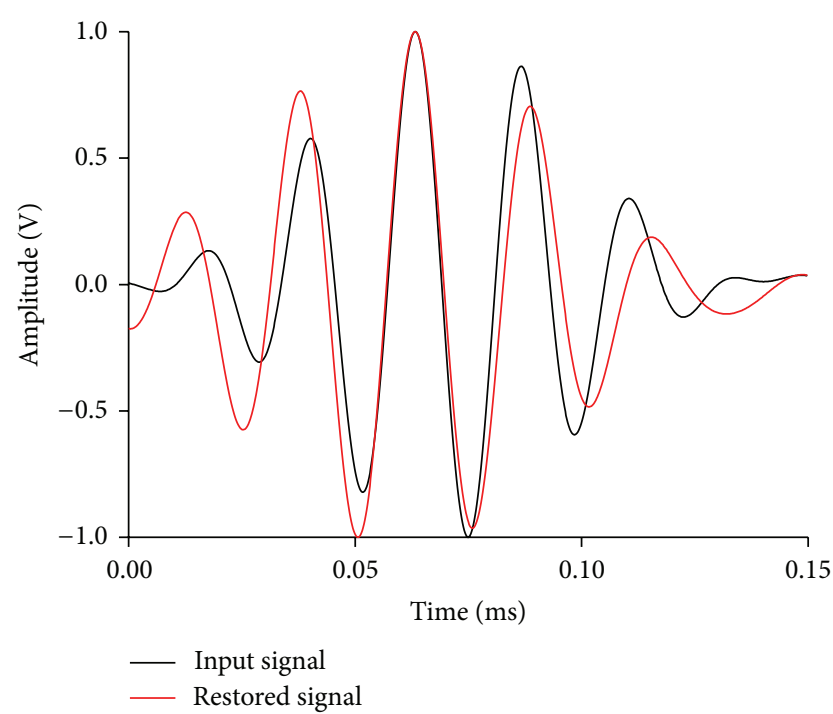

(a) Group A

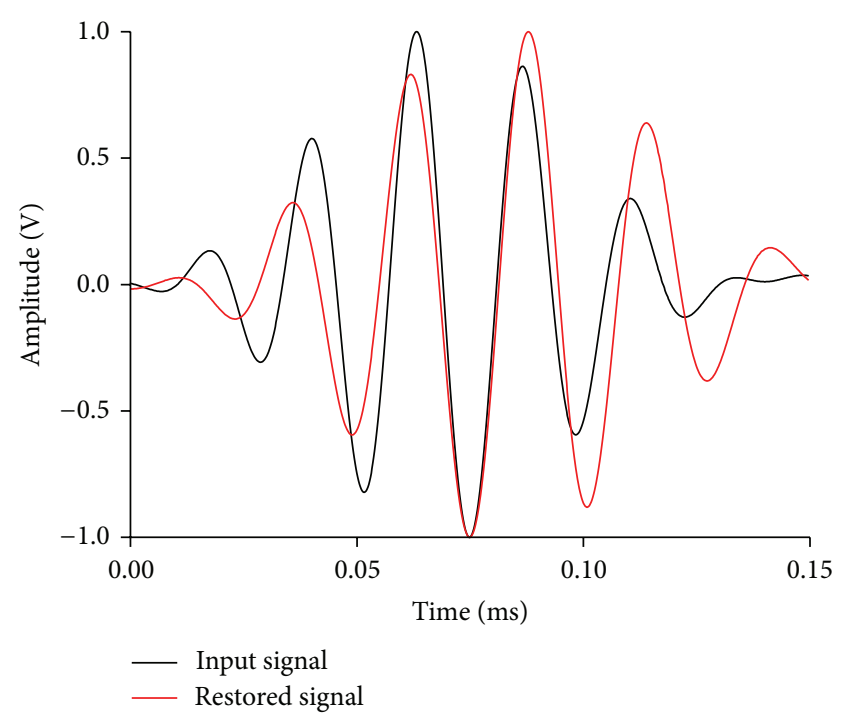

(b) Group B

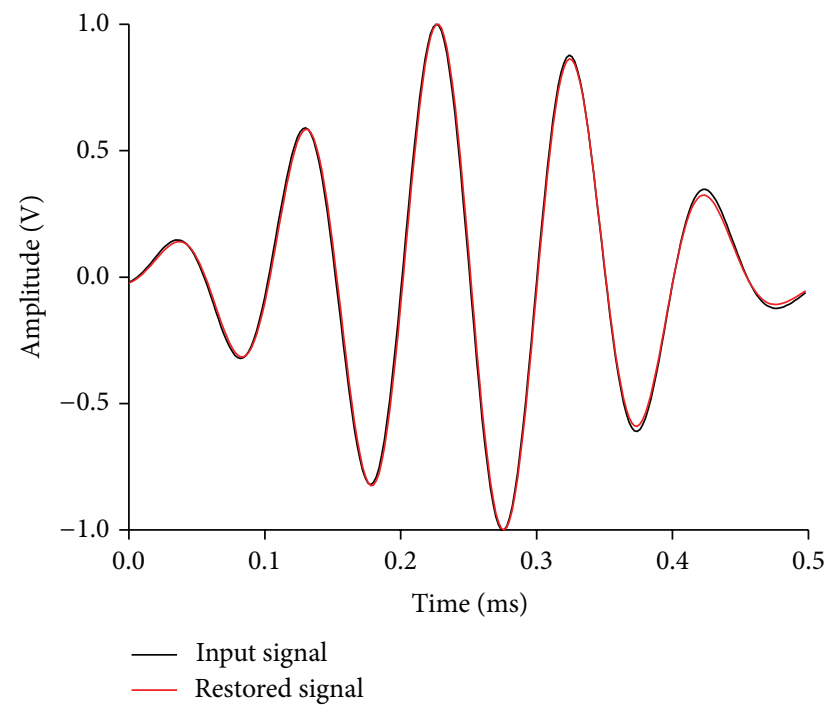

(c) Group C

FIGURE 10: Comparison of input signal and restored signal.

4.2.2. Process of the Experiment. The apparatus and process of experiment are the same as the verification experiment. The signal is still a five-peak pulse signal of $10 \mathrm{kHz}$. The signal processing method is the same as the verification experiment. The time history plots of the signal and time-reversed signal are shown in Figure 14.

\subsection{Experimental Results}

4.3.1. Compactness of Concrete under Different Diameter of Partition. This part aimed to fully understand whether the change of the diameter of partition has an influence on the compactness of concrete below the partition by comparison between specimens number 1 and number 5 . This part of specimen number 1 consists of six test groups, which are PZT1-PZT2(A), PZT2-PZT3(B), PZT4-PZT5(C), PZT5PZT6(D), PZT1-PZT3(E), and PZT4-PZT6(F). Corresponding to specimen number 1 , test groups of number 5 are PZT2PZT4(A), PZT4-PZT6(B), PZT3-PZT5(C), PZT5-PZT7(D), PZT2-PZT6(E), and PZT3-PZT7(F), respectively. Two SAs of these groups are used for sensor and actuator. Based on the process of verification experiment, the input signal is excited, received, time-reversed, and restored. Comparing the difference between the input signal and the restored signal, the compactness of the concrete can be identified. The compactness indices TR and SYM are shown in Figures 15 and 16 , respectively.

The TR values of these groups are greater than zero, and it means that the compactness of concrete in the area below the partition is not good. It can be seen that even the diameter of the partition is relatively large and the void area still exists. 
TABLE 1: Parameters of specimens.

\begin{tabular}{lcccccc}
\hline Number & $\begin{array}{c}\text { Size } \\
b \times h \times l / \mathrm{mm}\end{array}$ & $\begin{array}{c}\text { Diameter } \\
d / \mathrm{mm}\end{array}$ & $\begin{array}{c}\text { Strength grade } \\
\text { Artificial defects }\end{array}$ & $\begin{array}{c}\text { PZT patches } \\
\text { Detection type of compactness }\end{array}$ \\
\hline Number 1 & $300 \times 300 \times 3000$ & 150 & C30 & NO & NO & Compactness below partition \\
Number 2 & $300 \times 300 \times 3000$ & 150 & C30 & YES & NO & Artificial defects \\
Number 3 & $300 \times 300 \times 3000$ & 150 & C30 & YES & YES & Compactness below partition \\
Number 4 & $300 \times 300 \times 3000$ & 180 & C30 & NO & NO & Compactness of concrete in the tube \\
Number 5 & $300 \times 300 \times 3000$ & 180 & C30 & NO & YES & Contrast to Number 1 \\
\hline
\end{tabular}

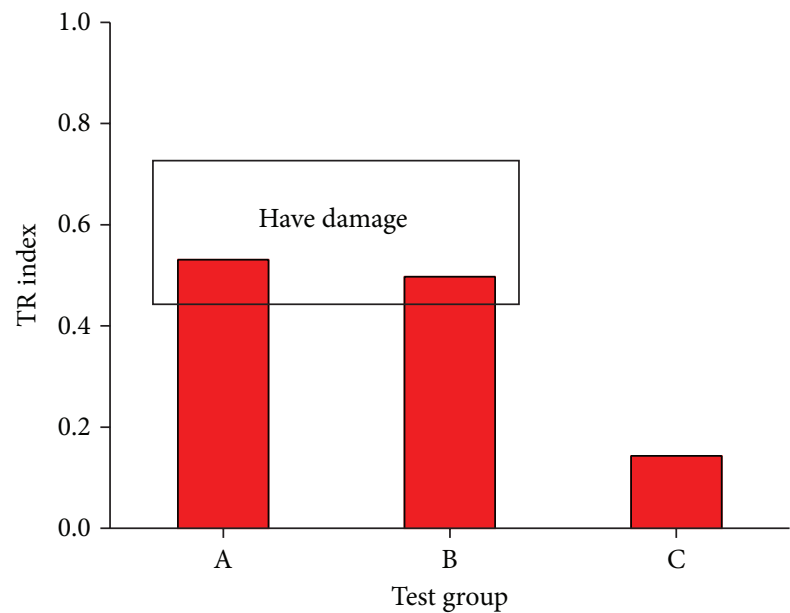

FIgURE 11: The TR index of these test groups.

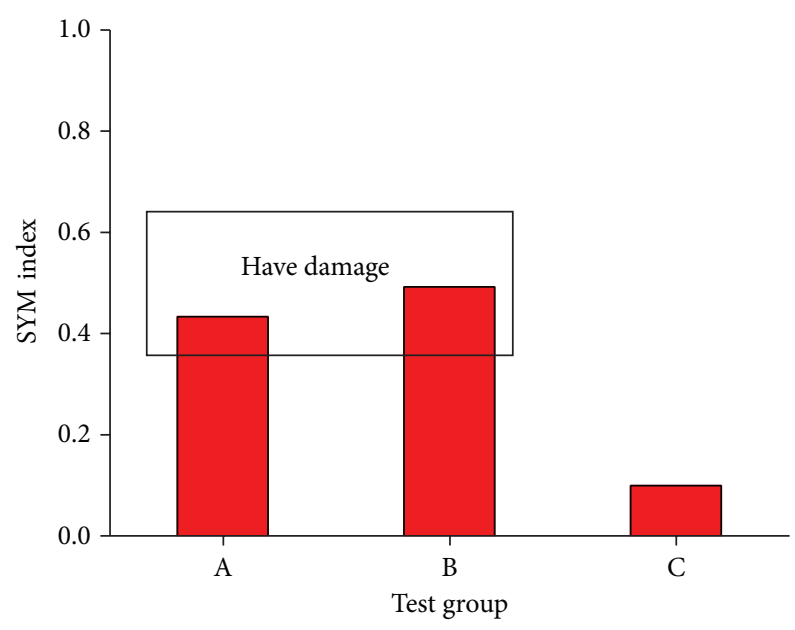

FIGURE 12: The SYM index of these test groups.

But the TR value of number 5 is smaller than that of number 1 ; it shows that the exchange for the diameter of the partition is effective for improvement of compactness of concrete below the partition. On this condition, the concrete can pass the partition smoothly and become denser. Otherwise, the TR values of test groups (E) and (F) are larger than the remaining ones because the void area of groups (E) and (F) is stacked with the one that is in the test groups (A) and (B), (C) and (D).
The same conclusion can be got from the SYM values of these test groups for specimens number 1 and number 5 .

4.3.2. Poor Cementation between Steel and Concrete. The purpose of this part is to detect the poor cementation between steel and concrete that exists or is simulated by artificial defects in specimens number 3 and number 5. Test groups of specimen number 3 consist of PZT2-PZT7(H) and PZT5PZT8(J). Corresponding to specimen number 3, test groups of number 5 are PZT1-PZT9(H) and PZT8-PZT10(J). The experimental process and signal processing are the same as the former. The compactness indices TR and SYM are shown in Figures 17 and 18, respectively.

Figures 17 and 18 show the comparison of groups number 3 and number 5 , and the TR value of test group $(J)$ is bigger than $(\mathrm{H})$. This is because the thickness of the artificial defect in test group $(\mathrm{J})$ is greatly larger than group $(\mathrm{H})$. However, the differences of TR value between two groups are not like that of artificial defect thickness, having nonlinear relationship between them. The same conclusion is suitable for specimen number 5. Namely, the poor cementation between steel and concrete existing in the whole specimen and the upper of the specimen is more serious. Therefore, the symmetry of the restored signal is violated and SYM values are bigger than zero. Poor cementation between steel and concrete can be verified similarly and much clearly by SYM values.

4.3.3. Compactness of Concrete for Different Sections. This part is to detect compactness of concrete for different sections in specimens number 3 and number 4 . The difference between them is the diameter of the partition. Test groups of specimen number 3 consist of PZT1-PZT3(A) and PZT4PZT6(B). Corresponding to specimen number 4, test groups of number 5 are PZT1-PZT3(A) and PZT4-PZT6(B). The experimental process and signal processing are the same as the former. The compactness indices TR and SYM are shown in Figures 19 and 20, respectively.

It is known that the TR value of test group (A) is smaller than test group (B) for specimens number 3 and number 4 , which means that the compactness of concrete under the section is better than that above it. Under the action of gravity, concrete is compressed and filled constantly. Strict casting process is also an important guarantee for the compactness of concrete. Less moisture, better curing, and sealing also do a good favor for the better compactness of concrete. 


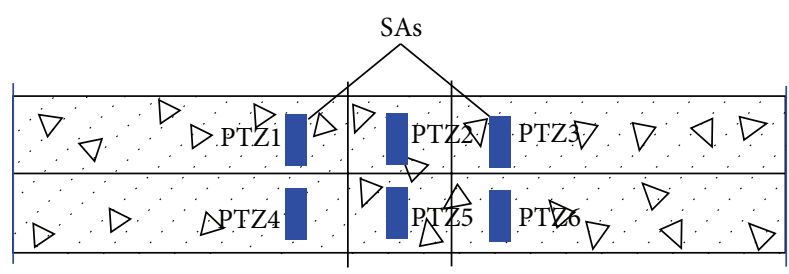

(a) number 1 specimen

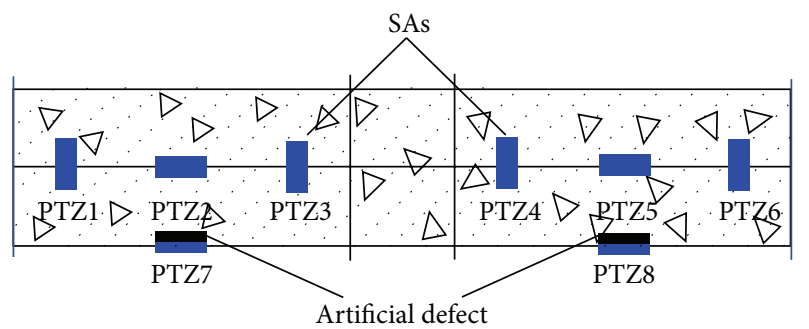

(c) number 3 specimen

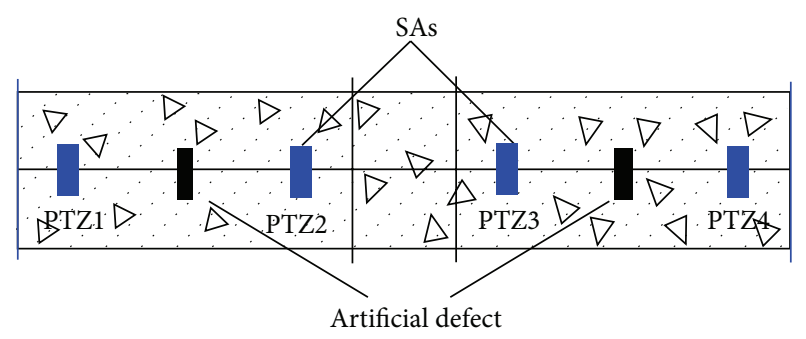

(b) number 2 specimen

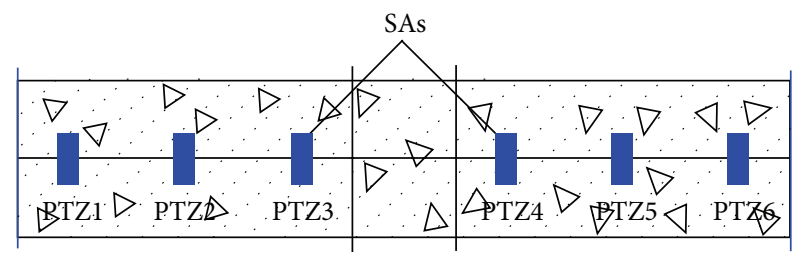

(d) number 4 specimen

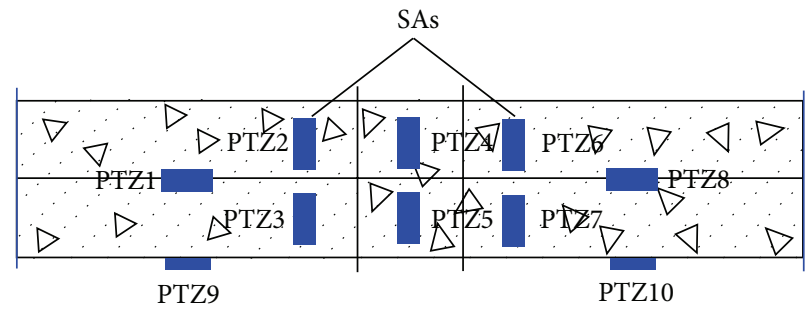

(e) number 5 specimen

FIGURE 13: The artificial defects and the location of SAs.

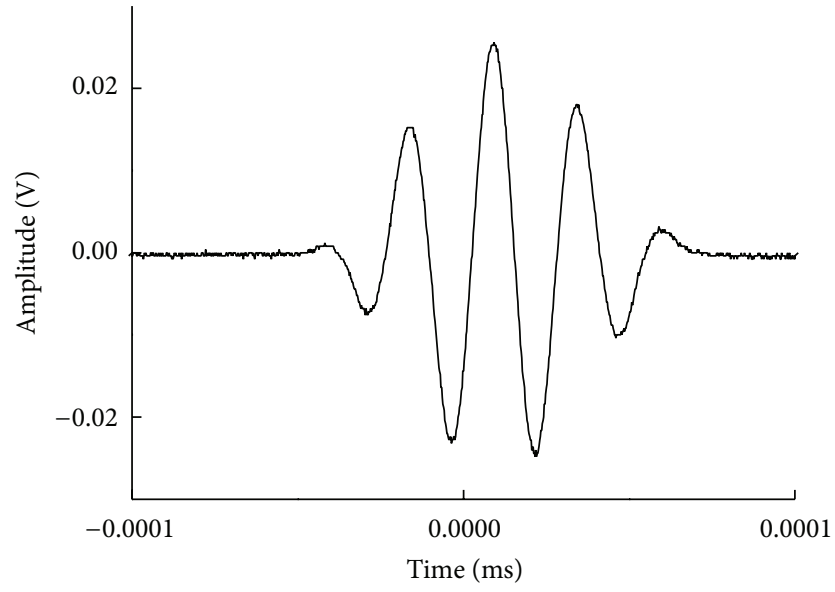

(a) Time history plots of the signal

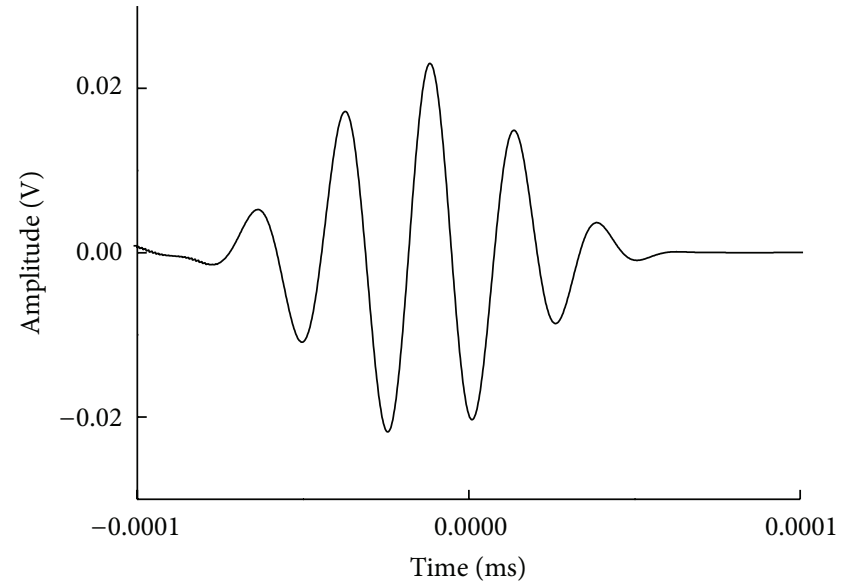

(b) Time-reversed signal

FIGURE 14: The history and time-reversed signal.

The TR value of test group (A) for specimen number 3 is slightly bigger than specimen number 4 , and the TR value of test group (B) is nearly as the same as each other, which means that the change of diameter of partition has something to do with the compactness of concrete below the section and has nothing to do with the up section. The same conclusion can be identified by SYM.

4.3.4. Compactness of Different Artificial Defects. In order to detect the compactness of concrete under different damage, 


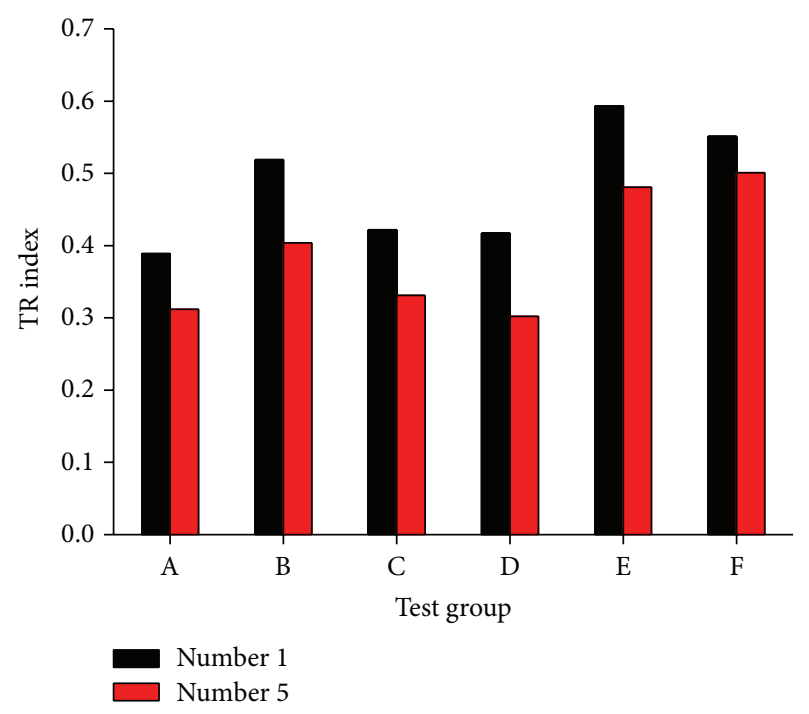

FIgURE 15: The TR index for specimens number 1 and number 5.

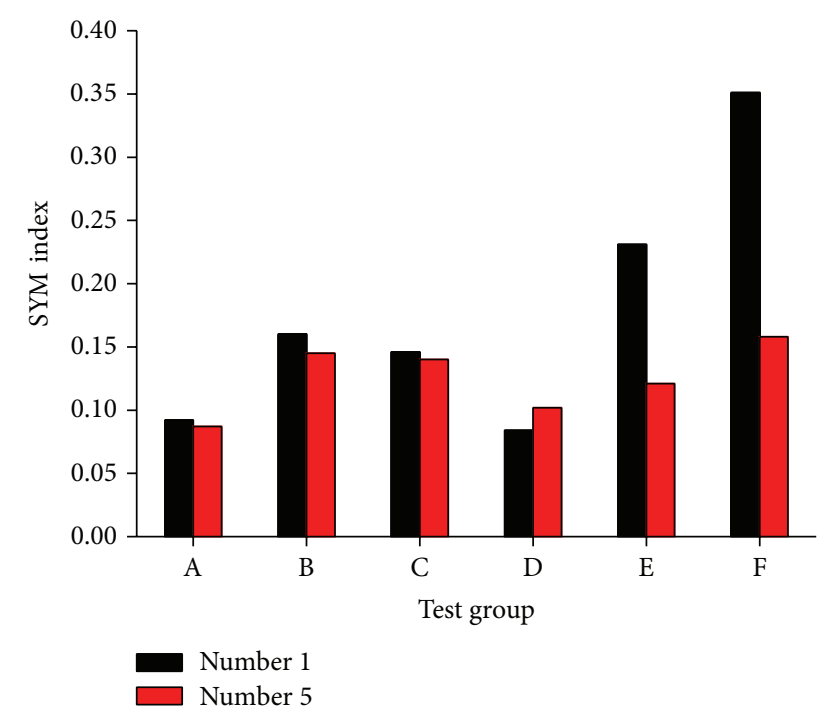

FIGURE 16: The SYM index for specimens number 1 and number 5.

specimen number 2 with two kinds of artificial defects of different thickness is designed. Test groups of specimen number 2 consist of PZT1-PZT2(A) and PZT3-PZT4(B). The experimental process and signal processing are the same as the former. The compactness indices TR and SYM are shown in Figures 21 and 22, respectively.

It can be seen that the TR index of test group (B) is nearly two times that of test group (B). The difference between each other is the thickness of artificial defects. The TR values of them are nearly the same as the thickness. It is clear that the artificial defects can be detected successfully and the detected area is consistent with the actual condition when any of the test groups is employed as actuator and sensor. It can be found that the damage areas can be successfully detected. The experimental results show that the proposed approach can effectively evaluate the damage existence and location.

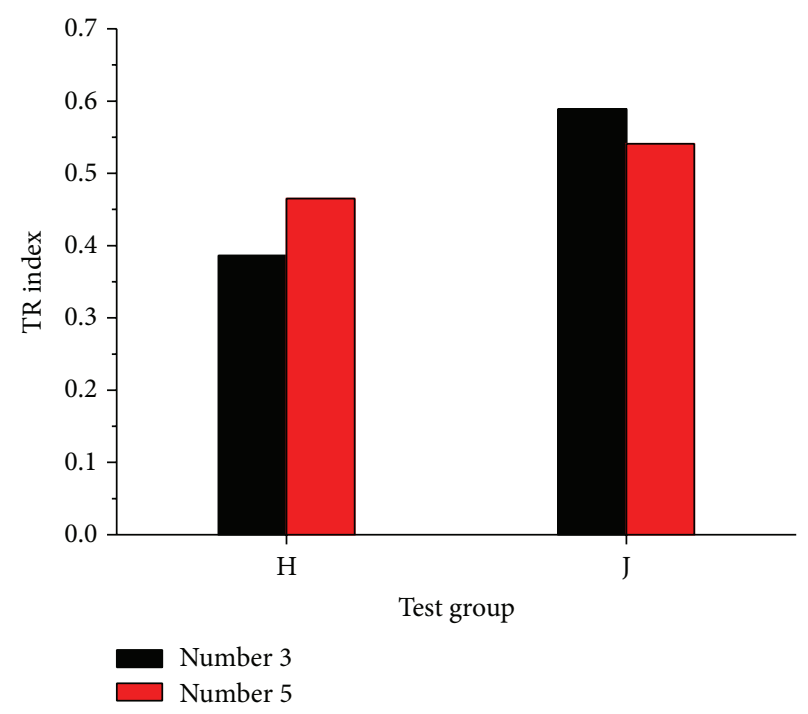

FIgURE 17: The TR index for specimens number 3 and number 5 .

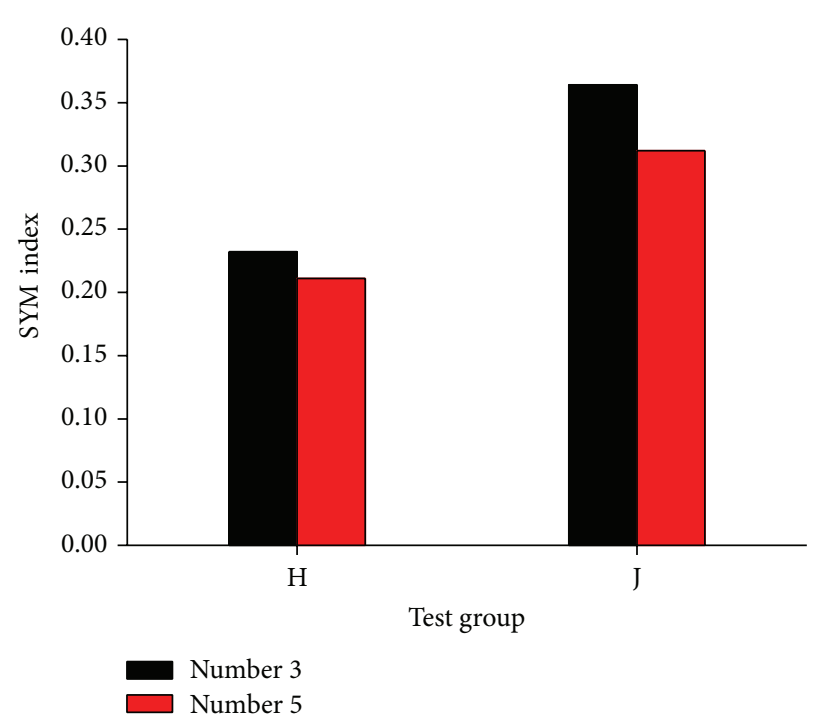

FIgURE 18: The SYM index for specimens number 3 and number 5.

\section{Conclusions}

In this paper, a detection approach for the compactness of concrete using two damage indices which are defined with the time reversal theory on the measurements of SAs installed in the CFST column and excited by smart aggregates in the concrete was developed. The effectiveness of the proposed approach was experimentally verified with a CFST model column. A five-peak pulse signal of $10 \mathrm{kHz}$ was employed to excite smart aggregates which act as actuators in concrete. The two proposed damage indices were employed to identify the existence and location of the artificially mimicked damage areas and real one. The results showed that the detected areas are satisfactorily in agreement with the predesigned damage conditions. 


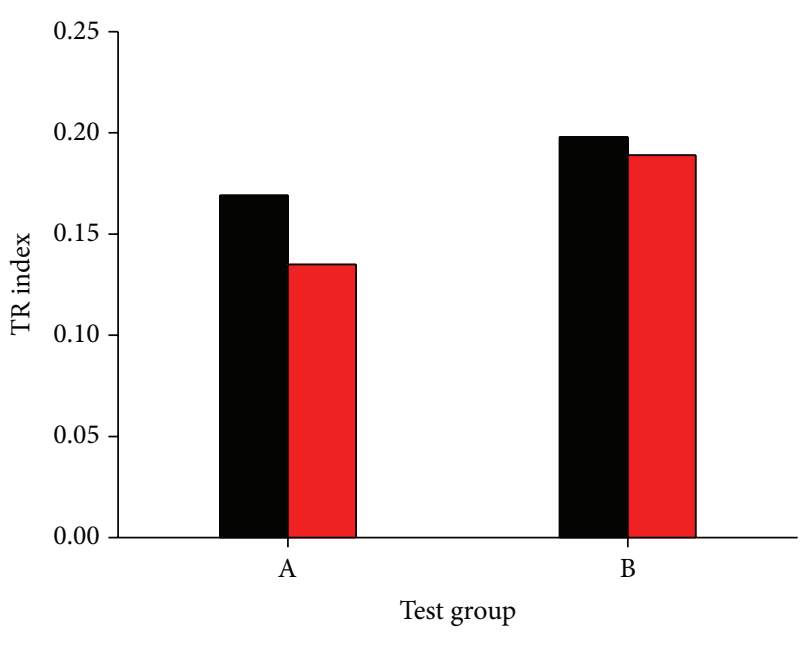

Number 3

Number 4

FIgURE 19: The TR index for specimens number 3 and number 4.

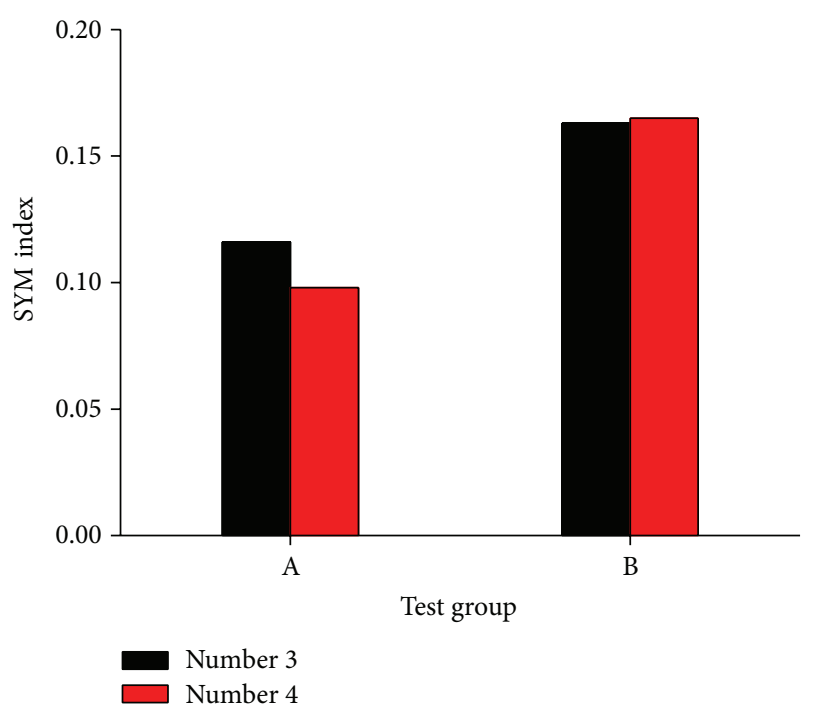

FIGURE 20: The SYM index for specimens number 3 and number 4.

The conclusion is as follows.

(1) The void of concrete below the partition and poor cementation between steel and concrete are inevitable in the concrete in filled steel tube columns. The only difference is the degree of the damage.

(2) The compactness of concrete below the section is better than that above it.

(3) For double partition, the compactness of concrete below the lower one is worse than the high one. Increasing the diameter of the partition does a good favor for the compactness of concrete below the partition. Therefore, it is a better way to improve the compactness of concrete by increasing the diameter

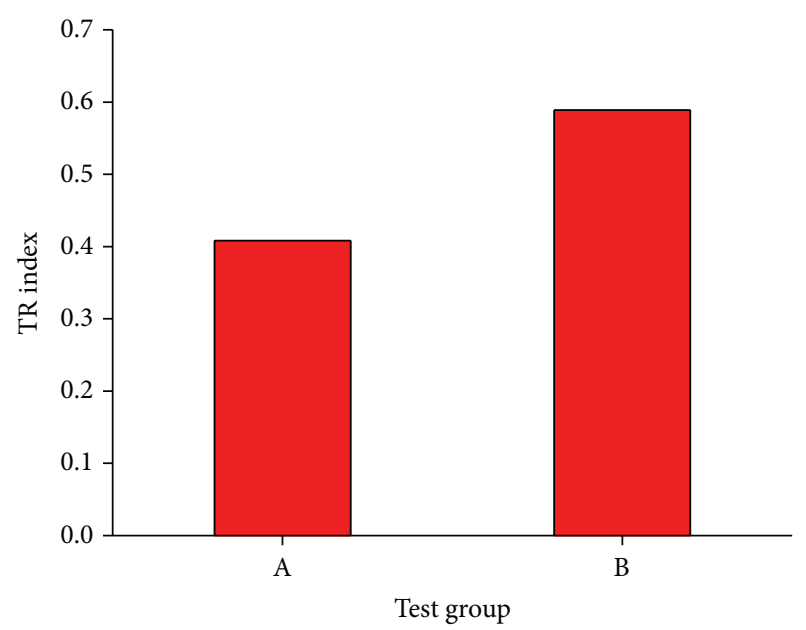

FIgURE 21: The TR index for specimen number 2.

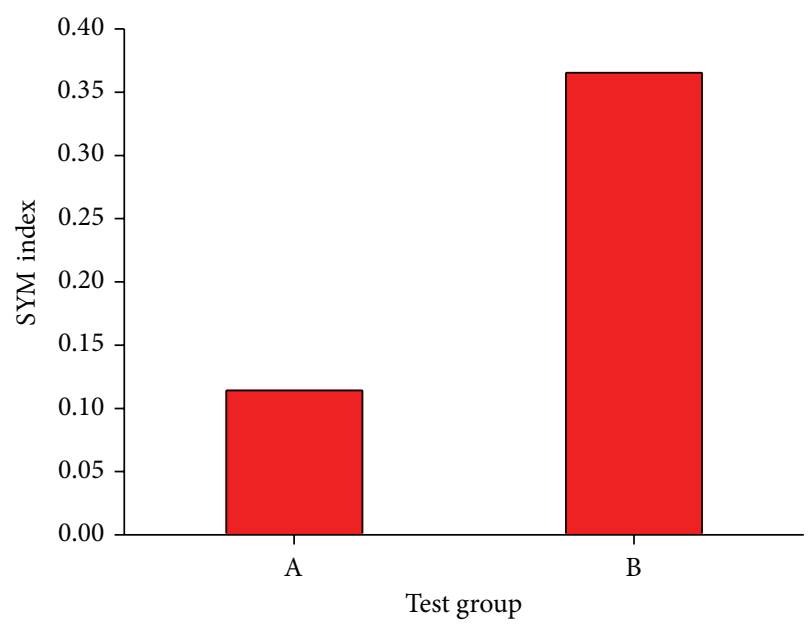

FIGURE 22: The SYM index for specimen number 2.

of the column. Therefore, it can be an important guarantee for load-carrying capacity and in the ductility of the CFSTC.

Moreover, the damage index defined with the TR and SYM is sensitive to the damage. The proposed PZT-based SAs and sensing techniques and the corresponding analysis approach have great potential to be applied in practice for the inaccessible damage detection of CFST engineering structures.

\section{Conflict of Interests}

The authors declare that there is no conflict of interests regarding the publication of this paper.

\section{Acknowledgments}

This work was financially supported in part by the National Natural Science Foundation of China (51278313 and 51308357), the Natural Science Foundation of Liaoning 
Province (201202180), the Science Foundation of Liaoning Education Department (L2012214), and Key Laboratory Foundation of Liaoning Province (JG2009-18), as well as Angang Construction Group 2011 Foundation.

\section{References}

[1] M. Saafi and T. Sayyah, "Health monitoring of concrete structures strengthened with advanced composite materials using piezoelectric transducers," Composites $B$, vol. 32 , no. 4, pp. 333342, 2001.

[2] C. S. Wang, F. Wu, and F.-K. Chang, "Structural health monitoring from fiber-reinforced composites to steel-reinforced concrete," Smart Materials and Structures, vol. 10, no. 3, pp. 548$552,2001$.

[3] F. Wu and F.-K. Chang, "Debond detection using embedded piezoelectric elements in reinforced concrete structures. Part I: experiment," Structural Health Monitoring, vol. 5, no. 1, pp. 5-15, 2006.

[4] S. Yan and W. Sun, "Experimental research on crack damage detection of concrete beam based on PZT wave method," Concrete, vol. 234, no. 4, pp. 20-23, 2010 (Chinese).

[5] B. H. Qi, S. Yan, F. Liu, B. He, and J. Fu, "Diagnostic test about density of concrete filled steel tube column with smart aggregates," Journal of Shenyang Jianzhu University, vol. 28, no. 3, pp. 491-496, 2012 (Chinese).

[6] M. Fink, "Time-reversed acoustics," Scientific American, vol. 281, no. 5, pp. 91-97, 1999.

[7] G. Song, H. Gu, Y. L. Mo, T. T. C. Hsu, and H. Dhonde, "Concrete structural health monitoring using embedded piezoceramic transducers," Smart Materials and Structures, vol. 16, no. 4, article 003, pp. 959-968, 2007.

[8] S. Yan, W. Sun, G. Song et al., "Health monitoring of reinforced concrete shear walls using smart aggregates," Smart Materials and Structures, vol. 18, no. 4, Article ID 047001, pp. 1-6, 2009.

[9] T. H. Yi and H. N. Li, "Methodology developments in sensor placement for health monitoring of civil infrastructures," International Journal of Distributed Sensor Networks, vol. 2012, Article ID 612726, 11 pages, 2012.

[10] V. Bottega, A. Molter, O. A. A. da Silveira, and J. S. O. Fonseca, "Simultaneous piezoelectric actuator and sensor placement optimization and control design of manipulators with flexible links using SDRE method," Mathematical Problems in Engineering, vol. 2010, Article ID 362437, 23 pages, 2010.

[11] H. S. Shang, T. H. Yi, and L. S. Yang, "Experimental study on the compressive strength of big mobility concrete with nondestructive testing method," Advances in Materials Science and Engineering, vol. 2012, Article ID 345214, 6 pages, 2012.

[12] T. H. Yi, H. N. Li, and H. M. Sun, "Multi-stage structural damage diagnosis method based on "energy-damage" theory," Smart Structures and Systems, vol. 12, no. 3-4, pp. 345-361, 2013.

[13] B. Xu, T. Zhang, G. Song, and H. Gu, "Active interface debonding detection of a concrete-filled steel tube with piezoelectric technologies using wavelet packet analysis," Mechanical Systems and Signal Processing, vol. 36, pp. 7-17, 2013.

[14] Q. Huang, B. Xu, B. Li, G. Song, and J. Teng, "Monitoring for large cross-section CFSTs of a super high-rise building with piezoceramic actuators and sensors," Advanced Materials Research, vol. 163-167, pp. 2553-2559, 2011.

[15] H. W. Park, H. Sohn, K. H. Law, and C. R. Farrar, “Time reversal active sensing for health monitoring of a composite plate," Journal of Sound and Vibration, vol. 302, no. 3, pp. 5066, 2004.

[16] S. D. Kim, C. W. In, K. E. Cronin, H. Sohn, and K. Harries, "Reference-free NDT technique for debonding detection in CFRP-strengthened RC structures," Journal of Structural Engineering, vol. 133, no. 8, pp. 1080-1091, 2007. 


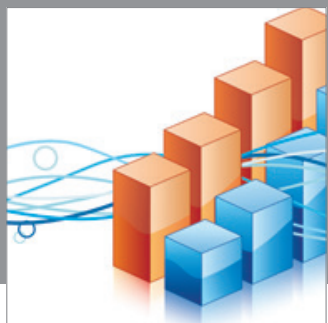

Advances in

Operations Research

mansans

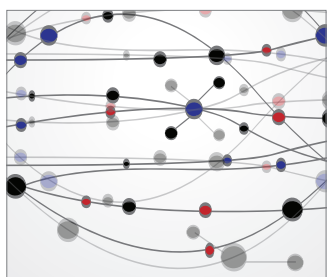

The Scientific World Journal
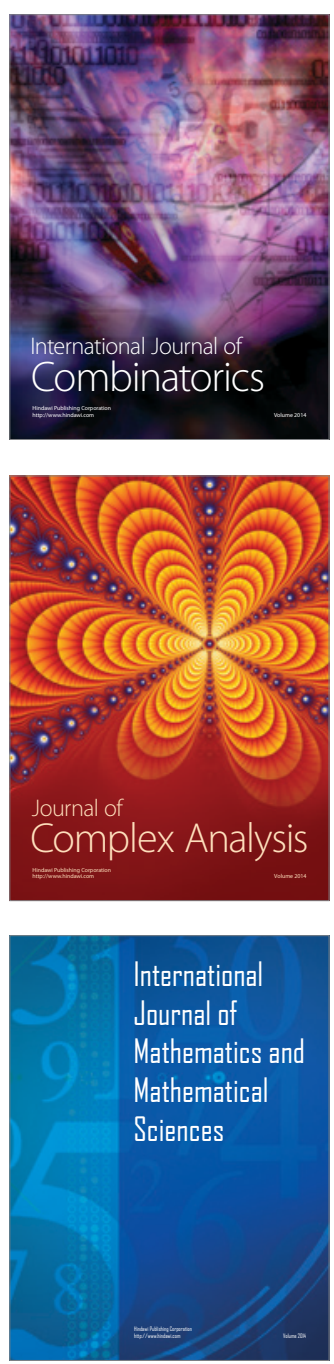
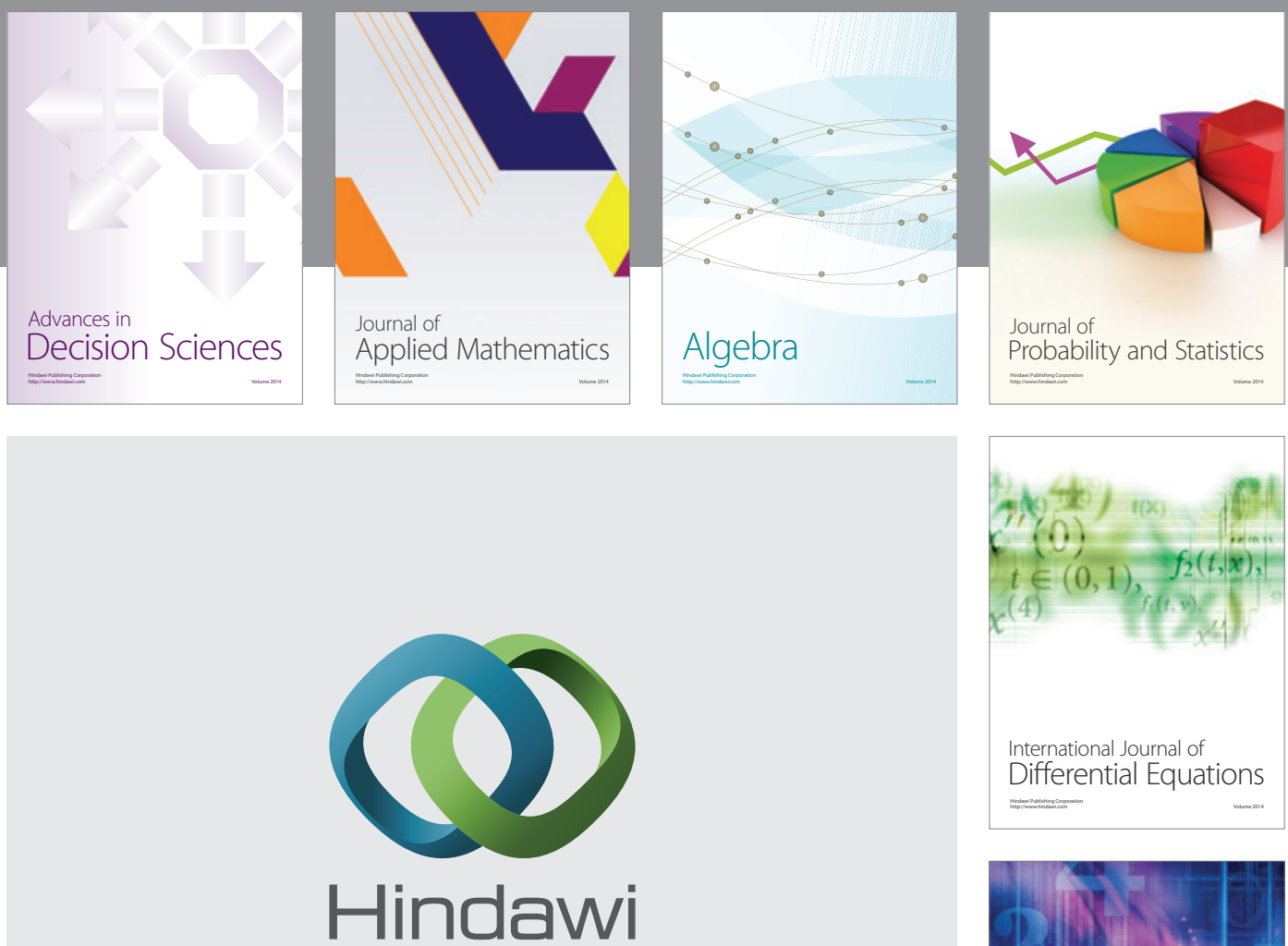

Submit your manuscripts at http://www.hindawi.com
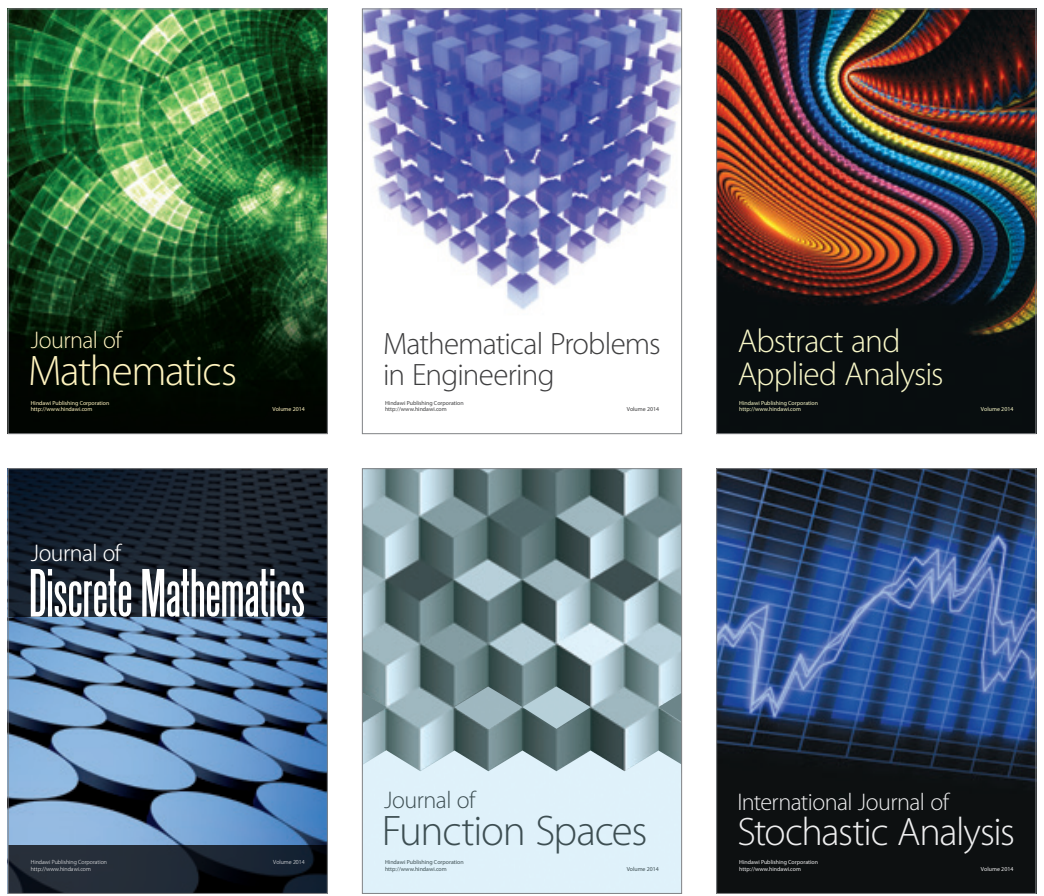

Journal of

Function Spaces

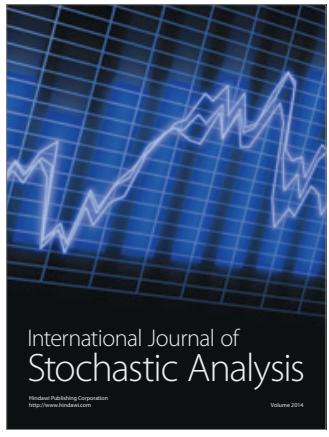

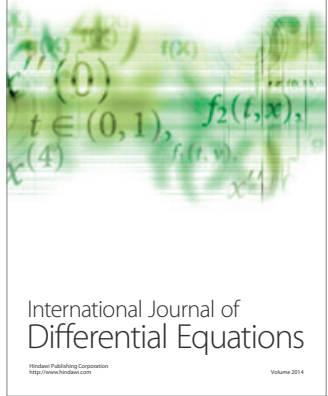
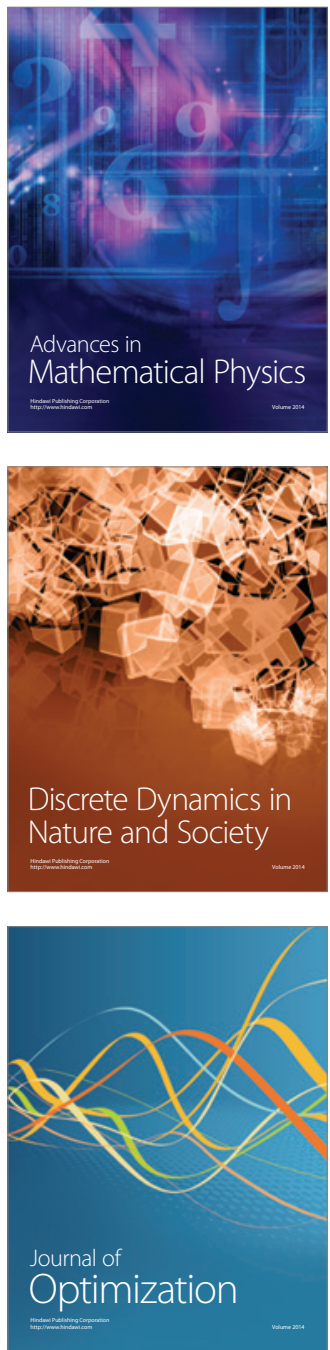